\title{
RACIONALIDADES PEDAGÓGICAS QUE FUNDAMENTAM A LICENCIATURA EM EDUCAÇÃO DO CAMPO
}

\author{
Pedagogical rationalities which found the bachelor in education of the field
}

\author{
Raimunda Alves Melo ${ }^{1}$ \\ Antonia Dalva França-Carvalho ${ }^{2}$
}

\begin{abstract}
RESUMO: O estudo em referência decorre de pesquisa de doutorado, desenvolvida junto ao Programa de Pós-graduação em Educação da Universidade Federal do Piauí (UFPI), a qual analisa as mudanças da prática educativa de professores que trabalham em escolas do campo após a participação no Curso Licenciatura em Educação do Campo (LEdoC). O recorte apresentado objetiva discutir as diferentes racionalidades pedagógicas que orientam os processos formativos do curso de Licenciatura em Educação do Campo da Universidade Federal do Piauí, Campus de Teresina. As discussões que embasam as referidas etapas, encontram-se apoiadas em teóricos, como: Contreras (2012), Formosinho (2009), Freire (2013; 2014), Molina; Hage (2015), Pérez Gómez (2000), Pimenta; Lima (2012), entre outros. Na produção dos dados, empregou-se a análise documental, proposta por Richardson (2012). Os resultados apontam que diferentes perspectivas fundamentam a formação e prática educativa de professores, evidenciando a complexidade do ser professor e a necessidade de que esse profissional adquira/desenvolva um leque de conhecimentos e saberes necessários ao exercício de sua profissão, assegurando a efetividade e qualidade social da ação educativa.
\end{abstract}

Palavras-chave: Formação de professores. Racionalidade pedagógica. Prática docente.

ABSTRACT: This study is based on a PhD research developed by the Postgraduate Program in Education of the Federal University of Piauí (UFPI), which analyzes the changes in the educational practice of teachers working in rural schools after attending the course Degree in Field Education (LEdoC). The clipping presented aims to discuss the different pedagogical rationalities that guide the formative processes of the Undergraduate Course in Field Education at the Federal University of Piauí, Teresina Campus. The discussions that support these stages are supported by theorists such as: Contreras (2012), Formosinho (2009), Freire (2013; 2014), Molina; Hage (2015), Pérez Gómez (2000), Pimenta; Lima (2012), among others. In the production of the data, we used the documentary analysis, proposed by

\footnotetext{
${ }^{1}$ Doutora em Educação pela Universidade Federal do Piauí (UFPI). Professora do Curso de Licenciatura em Educação do Campo da UFPI. E-mail: raimundinhamelo@yahoo.com.br

2 Doutora em Educação pela Universidade Federal do Ceará (UFC). Professora da Universidade Federal do Piauí (UFPI). E-mail: adalc@uol.com.br
}

Cadernos Cajuína, V. 4, N. 1, 2019, p. 22 - 40.

ISSN: 2448-0916 
Richardson (2012). The results point out that different perspectives base the formation and educational practice of teachers, evidencing the complexity of being a teacher and the need for this professional to acquire / develop a range of knowledge and knowledge necessary for the exercise of their profession, ensuring the effectiveness and social quality of educational action. Thus, the challenge is not only for the Degree in Field Education, but also for all policies of teacher training, is to develop training processes that provide mastery of the knowledge of the area that teaches and the methodology to teach, ensuring that the formation is based on principles such as reflection and criticality, so that the educator reflects and becomes aware that his responsibility is with the student and the community in which he is inserted.

Keywords: Teacher education. Pedagogical Rationale. Teaching practice. Training. Rationality. Politics.

\section{CONSIDERAÇÕES INICIAIS}

Nos últimos quinze anos, movimentos sociais e sindicais rurais organizaramse e desencadearam um processo nacional de luta pela garantia de seus direitos, articulando às exigências do direito à terra às reinvindicações pelo direito a uma educação escolar e comunitária que respeite, valorize e se aproprie dos saberes culturais dos alunos e da comunidade local, como elemento integrante do projeto pedagógico da escola, notadamente, da formação dos estudantes. Essa proposta educativa, denominada Educação do $\mathrm{Campo}^{3}$, é parte complementar de um projeto social mais amplo, que objetiva também, o direito à terra, à moradia, à justiça social, à saúde e à sobrevivência da população do campo.

Resultado dessa luta, o Programa de Apoio à Formação Superior em Licenciatura em Educação do Campo (PROCAMPO), criado em 2007, tem como objetivo, apoiar a implementação de cursos regulares nas instituições públicas de Ensino Superior, voltados especificamente, para a formação de educadores para a docência em escolas rurais nas séries finais do Ensino Fundamental e no Ensino Médio. Sua proposta formativa parte do princípio de que, se consideradas as especificidades da Educação do Campo, os professores podem ser formados como

\footnotetext{
${ }^{3}$ Segundo Fernandes (2008), a Educação do Campo é uma concepção que pode provocar transformações no cenário da educação brasileira, visto que compreende o resgate do espaço camponês, não apenas como ambiente de escolarização, mas como território de relações sociais, de cultura, de produção, de relação com a natureza, enfim, como território de vida.
}

Cadernos Cajuína, V. 4, N. 1, 2019, p. 22 - 40.

ISSN: 2448-0916 
intelectuais orgânicos ${ }^{4}$ na luta contra a hegemonia capitalista, que se apropria da educação como um elemento fundamental para a formação de mão de obra voltada para atender apenas às demandas do mercado de trabalho (MOLINA; HAGE, 2015).

A Licenciatura em Educação do Campo foi delineada por um Grupo de Trabalho $(\mathrm{GT})^{5}$, composto por professores e pesquisadores da área da Educação do Campo e por integrantes de movimentos sociais organizados e possui as seguintes diretrizes: a) seu objeto é a escola de educação básica, com ênfase na organização das escolas e no trabalho pedagógico para os anos finais do Ensino Fundamental e do Ensino Médio; b) seu objetivo é preparar educadores para atuar na docência, na gestão de processos educativos escolares e na gestão de processos educativos comunitários; c) sua organização curricular prevê etapas presenciais (equivalentes a semestres regulares), ofertados em regime de alternância entre Tempo Escola (TE) e Tempo Comunidade (TC); d) sua matriz curricular desenvolve uma estratégia multidisciplinar de trabalho docente, organizando os componentes curriculares, a partir de quatro áreas do conhecimento: Artes, Literatura e Linguagem; Ciências Humanas e Sociais; Ciências da Natureza e Matemática e Ciências Agrárias (MOLINA, 2015).

Essas diretrizes têm como fundamento, as especificidades do perfil do educador para atuação nas escolas do campo, uma formação cujo delineamento da proposta visa à construção de um projeto político pedagógico específico para as escolas do campo, bem como o envolvimento desse intelectual orgânico, com questões políticas, econômicas e sociais que desafiam a permanência e a sobrevivência das populações do campo, incluindo aspectos relativos à justiça

${ }^{4} \mathrm{O}$ termo, que se consolidou pelo uso, significa que a luta é contra uma hegemonia estabelecida, objetivando a construção de uma nova hegemonia, e que por isso, corresponde a um projeto de classe distinto. A palavra hegemonia é usada com base nos postulados do filósofo italiano Antonio Gramsci para descrever o processo de dominação pelos mais diversos veículos comunicacionais.

${ }^{5}$ Segundo Molina (2015), a partir da intensa cobrança dos movimentos sociais que seguiam pressionando para o atendimento das pautas da II Conferência Nacional de Educação do Campo, foi instituído um Grupo de Trabalho (GT), que ficou responsável pela elaboração da proposta que deveria subsidiar a Secretaria de Educação Continuada, Alfabetização, Diversidade e Inclusão (SECADI), na proposição ao Ministério da Educação (MEC), de uma proposta de formação de educadores campo. Após os encontros específicos do GT, para dar forma ao primeiro desenho da política de formação de educadores do campo, foram realizadas também, com suas representações, alguns encontros em que submeteu-se ao debate, a proposta elaborada, para chegar-se à versão a ser apresentada às várias instâncias do MEC, responsáveis pela implementação do Programa, que, finalmente, aprovou o desenho das Licenciaturas em Educação do Campo.

Cadernos Cajuína, V. 4, N. 1, 2019, p. 22 - 40.

ISSN: 2448-0916 
social. O alcance desse objetivo, segundo Molina (2015), implica o desenvolvimento de processos formativos que considerem a realidade histórico-social na qual os educandos/educadores estão inseridos, suas necessidades formativas para a vida escolar/acadêmica e cotidiana e, de igual modo, a indispensável relação entre teoria e prática.

A concepção de formação da Licenciatura em Educação do Campo (LEdoC) está intimamente ligada ao modelo de desenvolvimento e sociedade pensado para o campo, pois, fundamentado em Gramsci (1991), o Movimento da Educação do Campo $^{6}$ acredita que a realidade é construída pelas ações dos atores sociais e que, para atuar na e sobre a mesma, o homem deve compreendê-la, enquanto subsídio necessário para sua transformação. Assim, a escola do campo é parte do projeto de emancipação política e social da classe trabalhadora e os processos formativos para professores objetivam não só a aprendizagem de saberes e conhecimentos para atuação na docência e na gestão escolar e comunitária, mas também, o fortalecimento dos camponeses no empoderamento de suas lutas pela garantia dos direitos sociais a que fazem jus.

Nesse contexto, o Curso de Licenciatura em Educação do Campo (LEdoC), vinculado ao Centro de Ciências da Educação, da Universidade Federal do Piauí (UFPI) é uma ação formativa estratégica, que busca assegurar a especificidade do campo e o atendimento a sua diversidade sociocultural. Destina-se a formação de educadores para as escolas do campo, na área de Ciências da Natureza, tem caráter regular e duração de quatro anos, sendo realizado em sistema de blocos semestrais.

Partindo dessas considerações introdutórias, o presente artigo tem como objetivo discutir as diferentes racionalidades pedagógicas que orientam os processos formativos do curso de Licenciatura em Educação do Campo, da Universidade Federal do Piauí, Campus de Teresina. Partimos do pressuposto de que, as políticas de formação de professores carecem de um olhar crítico sobre as racionalidades que fundamentam os processos formativos, objetivando entender a

\footnotetext{
${ }^{6}$ Segundo Silva (2011), o Movimento da Educação do Campo, composto por diferentes representações dos movimentos sociais e sindicais, pesquisadores e professores da área, surgiu no final da década de 90 , com o objetivo de refletir, expor a situação do povo do campo no Brasil, suas perspectivas e experiências, buscando a concretização de novas políticas para o campo, que possam contemplar projetos populares de desenvolvimento da população que residem nessas áreas.
}

Cadernos Cajuína, V. 4, N. 1, 2019, p. 22 - 40.

ISSN: 2448-0916 
relação dessas propostas com os diferentes interesses políticos, econômicos e sociais que permeiam o campo das políticas públicas.

\section{METODOLOGIA}

Realizamos este estudo, orientadas pelos vieses epistemológicos da pesquisa qualitativa crítica, compreendida como uma abordagem que, além de possibilitar uma compreensão do real, exposto e traduzido nos discursos dos interlocutores, também favorece a conscientização das pessoas para a mudança da realidade da qual fazem parte.

A pesquisa qualitativa crítica é uma modalidade que permite a inserção do pesquisador no contexto da investigação, aproximando-o do problema a ser pesquisado, bem como dos interlocutores que vivenciam e compartilham uma dada realidade, marcada por diversas experiências profissionais e pessoais, sujeitas a uma relação que se caracteriza pela sua natureza dinâmica, viva, interativa e contraditória.

Um dos aspectos mais relevantes da pesquisa qualitativa, inspirada pela teoria crítica, refere-se à interpretação das informações, sendo necessário que o pesquisador analise criteriosamente o objeto de estudo, observando o contexto histórico e sua relação com a atualidade, as informações explícitas e implícitas, de forma a comunicar a compreensão a respeito do resultado (KINCHELOE; MACLAREN, 2007).

Segundo Carspecken (2011), por meio da produção de conhecimentos, a pesquisa qualitativa crítica explicita as relações de poder e as injustiças sociais, contribuindo para a conscientização das pessoas e para a mudança social. Dessa forma, o pesquisador assume o compromisso em desvelar desigualdades sociais, oferecendo aos interlocutores, elementos teórico-práticos que efetivamente contribuam para a transformação social.

Para a produção dos dados, fizemos a análise documental do Projeto Pedagógico do Curso (PPC). Essa técnica é definida por Richardson (2012, p. 228), "como a que tem como objeto não os fenômenos sociais, quando e como se produzem, mas as manifestações que registram estes fenômenos e as ideias elaboradas a partir deles". A análise documental do PPC consistiu em um estudo rigoroso, realizado em três etapas: na primeira, denominada pré-análise, realizamos 
a seleção e leitura superficial do material; na segunda, intitulada análise do material, fizemos a codificação, categorização e quantificação das informações, mediante leituras atentas e repetidas do documento. Na última etapa, denominada tratamento dos resultados, realizamos as inferências e interpretações do documento e selecionamos recortes de trechos do mesmo para ilustrar as análises (RICHARDSON, 2012).

$\mathrm{Na}$ análise documental, utilizamos como dados, o texto do próprio PPC da LEdoC/UFPI e seus modos de operacionalização, analisando as teorias e tendências filosófico-pedagógicas que o fundamentam, os elementos norteadores da Educação do Campo contidos no documento, o currículo, as bibliografias indicadas, as práticas educativas sugeridas e desenvolvidas, bem como, os aspectos que revelam os desafios da formação de professores nesse curso.

\section{RACIONALIDADES PEDAGÓGICAS DA FORMAÇÃO E PRÁTICA DOCENTE}

Ao tratar sobre as diferentes racionalidades pedagógicas ${ }^{7}$ que fundamentam a formação de professores, Carvalho (2007) assevera que não é possível efetuar a análise ampla dos processos sociais e, sobretudo educacionais, sem considerar as diferentes racionalidades projetadas pelas díspares teorias do campo da educação, uma vez que, elas constituem um esforço para a obtenção de alternativas curriculares e metodológicas, voltadas para a formação de professores em suas diferentes dimensões profissionais.

Segundo Garcia (1999), diferentes orientações conceituais permeiam o campo das estruturas e racionalidades sobre a formação de professores. Essas concepções variam em função das diferentes abordagens e paradigmas norteadores do currículo, da imagem do professor e das perspectivas a respeito dos processos de formação. Elas também definem os processos de seleção, transmissão e produção do conhecimento, a escolha dos métodos e as estratégias utilizadas nos processos de formação.

Embora existam distintas formas para designar as estruturas de formação de professores, neste trabalho nos fundamentamos em Pérez Gómez (2000), que

\footnotetext{
${ }^{7}$ Segundo Carvalho (2007), a racionalidade pedagógica compreende o processo de reflexão sobre os motivos, julgamentos e decisões, os saberes da prática pedagógica, sua organização e sua distribuição na cultura docente em ação. Comporta em si uma teoria da educação que guia a prática educativa.
}

Cadernos Cajuína, V. 4, N. 1, 2019, p. 22 - 40.

ISSN: 2448-0916 
apresenta quatro perspectivas básicas, a saber: acadêmica, técnica, prática e reconstrução social. Desse modo, passamos agora, a analisar cada uma, com o objetivo de evidenciar como as mesmas se apresentam no Curso de Licenciatura em Educação do Campo da UFPI de Teresina.

Com o propósito de melhor ilustrar a análise, apresentamos recortes textuais do PPC da LEdoC/UFPI, a fim de fundamentar a análise documental. Temos consciência de que, ao analisar esse documento, buscando evidências dessas perspectivas, corremos o risco de que esta análise não abarque todo o leque de possibilidades interpretativas, bem como, os limites difusos e de difícil enquadramento, a respeito das concepções de formação que fundamentam o projeto pedagógico do referido curso.

\subsection{Racionalidade pedagógica acadêmica}

[...] a par dos conteúdos específicos, buscar-se-á ampliar os conhecimentos oferecidos aos graduandos, especialmente, aqueles voltados à prática educacional, permitindo saberes necessários para a atuação nas áreas de Ciências da Natureza.

(UFPI, 2013, p. 25)

Conforme está evidenciado na epígrafe, retirada do PPC de Licenciatura em Educação do Campo, a racionalidade acadêmica concebe a formação de professores como um processo de transmissão de conhecimentos científicos e culturais, cujo propósito é o domínio do saber científico pelo professor. Pérez Gómez (2000) afirma que existem dois enfoques relacionados a essa concepção de professor: o enciclopédico - visto como uma enciclopédia, um especialista das disciplinas que ministra, cuja competência é medida pelo acúmulo de conhecimentos disciplinares, dando pouca importância a formação didática; e o compreensivo entendido como um intelectual com compreensão sobre a estrutura da matéria que ensina. Em âmbito do PPC da LEdoC/UFPI, o professor é visto não como uma enciclopédia, mas como um intelectual, que tem "conhecimento criativo dos princípios e dos fatos de sua disciplina, assim como dos procedimentos metodológicos em sua produção" (UFPI, 2013, p. 355).

Ao tratar sobre essa perspectiva, Garcia (1999) afirma que, pelo caráter eminentemente científico do currículo da formação inicial, a ótica acadêmica ainda é 
predominante nos cursos de formação de professores. Concordamos com o autor, pois durante a formação inicial, considerada como um campo de conhecimentos, verificações de teorias e práticas, embora alguns estudantes já desempenhem funções docentes, cumprem estudos e atividades pertinentes ao fluxo curricular correspondente ao curso escolhido, cujo caráter é acadêmico, o que não impede que os processos formativos articulem o elo entre profissão, construção e apropriação do conhecimento científico pelo professor e deste com os saberes culturais dos alunos.

Formosinho (2009), ao tratar sobre a academização do ensino superior, considerada como "uma invasão pela lógica acadêmica, de áreas e níveis de decisão que, numa atividade que tem por missão formar professores, se devem manter no âmbito da lógica profissional" (p. 76), afirma que essa perspectiva promove, nos futuros professores, uma concepção de currículo como imposição de disciplinas, que, quando trabalhadas de forma fragmentada, não favorecem a interdisciplinaridade e o trabalho coletivo. Uma das consequências disso é o afastamento dos professores universitários das preocupações pragmáticas do contexto profissional e das dimensões profissionais no seu ensino, delegando essa tarefa apenas para os estudantes.

Apesar de muito criticada pelos pesquisadores da área de formação de professores, o rompimento com a lógica da academização do Ensino Superior não é um processo simples, tendo em vista que, a estrutura curricular, administrativa e pedagógica da maioria das instituições de ensino encontram-se histórica e culturalmente organizadas a partir desses princípios. Soma-se a isso, o fato dos professores universitários terem sido formados a partir dessa perspectiva, compreendendo a formação docente como um conjunto de conhecimentos científicos que precisam ser trabalhados a priori.

Em âmbito da LEdoC/UFPI de Teresina, observamos que as aulas dos professores universitários possuem enfoques predominantemente fundamentados na perspectiva acadêmica, caracterizada pela reprodução e apropriação de conhecimentos validados cientificamente pela academia, secundarizando as práticas educativas que favorecem a articulação e integração com os saberes da cultura camponesa e os saberes experienciais dos professores de escolas do campo. Contudo, as atividades desenvolvidos durante o TC, em ambiente real do licenciando, contribuem para a sua formação como educador-pesquisador, 
realizando pesquisas e práticas pedagógicas, contemplando outras perspectivas de formação.

\subsection{Racionalidade pedagógica técnica}

Os professores formados pelo Curso de Licenciatura em Educação no campo serão profissionais com competências e habilidades para dominar os conteúdos básicos que são objeto de ensinoaprendizagem no ensino fundamental e médio; dominar os métodos e técnicas pedagógicos que permitem a mediação do conhecimento para os diferentes níveis de ensino.

UFPI (2013, p. 30)

Desenvolvida no final da década de 30 , a perspectiva técnica é caracterizada por Pérez Gómez (2000, p. 356) como aquela em que "o ensino é concebido como uma ciência aplicada e o professor como um técnico que domina a aplicação do conhecimento científico". Reforça que essa ótica fundamenta-se na concepção positivista de conhecimento e prática, propondo que o professor "aprenda conhecimentos de sua área e desenvolva competências para a sua aplicação na prática" (2000, p. 357).

Conforme trecho do PPC da LEdoC/UFPI, citado como epígrafe desse subitem, o foco é capacitar o professor para dominar os conteúdos básicos e os métodos e técnicas pedagógicas. Nesse sentido, o modelo da racionalidade técnica compreende os processos de ensino como intervenção tecnológica, o professor como um técnico e a formação como treinamento para desenvolvimento de competências (GARCIA, 1999).

Contreras (2012) afirma que essa perspectiva relaciona-se com o domínio técnico demonstrado pelos professores na solução de problemas, ou seja, no conhecimento dos procedimentos adequados ao ensino e em sua aplicação inteligente. Segundo esse autor, o professor, como profissional técnico, compreende que sua ação consiste na aplicação de decisões técnicas. Ao reconhecer o problema diante do qual se encontra, ao ter claramente definidos os resultados que deve alcançar, ou quando tiver decidido qual é a dificuldade de aprendizagem de tal aluno ou grupo, seleciona entre o repertório disponível, o tratamento que melhor se adapta à situação e o aplica. 
Nessa racionalidade, o desenvolvimento de competências profissionais é considerada como uma questão mister na formação de professores, tendo em vista que, são elas que viabilizam a aplicação do conhecimento e da técnica. Assim, o papel do professor é aprender o domínio das técnicas propostas pelos especialistas e a formação tem como objetivo, treinar os docentes para o uso das mesmas (PÉREZ GÓMEZ, 2000). É válido salientar que, a partir da década de 90 ressurgem propostas hegemônicas de formação de professores fundamentadas no desenvolvimento de competências. A título de ilustração, mesmo se tratando de um curso com proposta contra-hegemônica, o PPC da LEdoC/UFPI faz referência a competências e habilidades previstas para os ingressos do curso.

Contudo, a proposta da LEdoC se contrapõe à racionalidade técnica, que considera os professores como meros executores de decisões alheias. Também se distancia dessa perspectiva, por não contemplar uma relação de subordinação entre professores e pedagogos, não supervalorizar o conhecimento especializado, tendo em vista que o currículo do curso se organiza por área de conhecimento e, principalmente, por considerar os professores como protagonistas de seu processo de formação e exercício da docência, com capacidades para tomar decisões e intervir no ambiente em que atuam, seja ele, a escola ou a comunidade.

Pérez Gómez (2000, p. 359-360) afirma que a perspectiva técnica é limitada, uma vez que "supõe uma crítica da cega ação empírica. Ao propor a utilização do conhecimento do método científico na análise da prática e na derivação de regras que normatizam e regulam a intervenção do professor/a". Segundo esse autor, os problemas da prática social não podem ser reduzidos a questões meramente instrumentais, na qual a tarefa do docente fica limitada a escolha e aplicação das técnicas. A realidade é complexa e imprevista, demandando conhecimentos e saberes práticos dos professores.

No entanto, apesar das limitações enfatizadas anteriormente, não devemos proceder uma recusa generalizada da perspectiva técnica e de sua utilização na prática educativa, uma vez que, o trabalho docente demanda domínio dos conteúdos básicos e dos métodos e técnicas pedagógicas que permitem a mediação do conhecimento para os diferentes níveis de ensino, conforme enfatiza o PPC da LEdoC/UFPI. 


\subsection{Racionalidade pedagógica prática}

[...] Oferecer condições metodológicas e práticas para que os educadores em formação possam tornar-se agentes efetivos na construção e reflexão dos projetos pedagógicos das escolas do e no campo onde atuam. (UFPI, 2013, p. 27)

Na perspectiva prática, a exemplo do que ilustra a epígrafe acima, o ensino é entendido como uma "atividade complexa, desenvolvida em cenários singulares, claramente determinados pelo contexto" (PÉREZ GÓMEZ, 2000, p. 365). Segundo o pesquisador, essa perspectiva possui dois enfoques: o tradicional e o que enfatiza a prática reflexiva. O enfoque tradicional se apresenta vivo e exerce notável influencia no pensamento comum da sociedade e no pensamento dos próprios professores, considerando que eles aprendem por meio de um processo de tentativas e erros, no qual se organiza a sabedoria profissional, transmitida de geração em geração. Esse autor assegura que os conhecimentos da prática estão saturados de senso comum, impregnados dos vícios e obstáculos epistemológicos, do saber de opinião e da ideologia dominante de caráter conservador.

Considerando as proposições desse pesquisador, o desafio que está para os professores das escolas do campo, que participam da LEdoC é o de identificar e refletir sobre os saberes que compõem suas práticas educativas, verificando as teorias que os fundamentam, bem como, os vícios e concepções ideológicas conservadores como um dos primeiros passos para a mudança da prática educativa.

Segundo a racionalidade prática, o professor é visto como um artesão, artista ou profissional e sua formação tem como eixo, a aprendizagem "da prática, para a prática e a partir da prática”. Conforme Garcia (1999, p. 39) essa perspectiva também é muito presente na formação inicial de professores e "o modelo de aprendizagem associado a esta orientação é o da aprendizagem pela experiência e observação". Ao tratar sobre os saberes da prática, Tardif (2011) afirma que o saber dos professores é plural e temporal, uma vez que é adquirido no contexto de uma história de vida e de uma carreira profissional, ou seja, ensinar supõe aprender a ensinar, aprender progressivamente os saberes necessários à realização do trabalho docente, através da experiência profissional e pessoal do professor. 
Formosinho (2009) diz que a formação de professores é um processo por meio do qual se realiza a promoção da aprendizagem dos saberes profissionais inerentes ao desempenho docente. Assevera que a aprendizagem dessa profissão não se faz apenas nos processos de formação inicial e continuada, mas também, por meio das experiências com os alunos, na observação cotidiana do desempenho dos professores na educação básica e superior, nas experiências de educação informal e não formal, fato que diferencia a aprendizagem da docência das demais profissões.

Ainda sobre os saberes da prática, Tardif (2011) afirma que uma parcela relevante do saber docente ocorre com o trabalho efetivo (práxis), ou seja, o saber dos professores não é um conjunto de conteúdos cognitivos definidos de uma vez por todas, mas um processo em construção, ao longo de uma carreira profissional na qual o professor aprende progressivamente a dominar seu ambiente de trabalho, ao mesmo tempo em que se insere nele e o interioriza, por meio de regras de ação que se tornam parte integrante de sua consciência pacífica.

Dessa forma, ao desenvolver processos formativos para professores, é necessário considerar quais saberes da prática esses profissionais já possuem, que teorias fundamentam esses saberes, como os mesmos dialogam com as proposições teóricas do curso num processo analítico de reflexão crítica para que os eles tenham consciência de suas práticas, bem como, as relações que as envolvem. É nesse sentido que a perspectiva reflexiva da prática se apresenta como uma alternativa.

O enfoque reflexivo sobre a prática contrapõe-se a racionalidade técnica e expressa o desejo de superar "a relação linear e mecânica entre o conhecimento científico técnico e a prática na aula". Essa perspectiva parte do princípio de que, por ser uma atividade social e complexa, os professores enfrentam problemas de natureza prática, de natureza incerta, problemas imprevisíveis, que não são resolvidos com o emprego dos procedimentos técnicos, demandando dos mesmos, atitude criativa e reflexiva (PÉREZ GÓMEZ, 2000, p. 364).

Para Dewey (1979), a formação está diretamente ligada à ação reflexiva dos professores, sendo necessário três atitudes para que ela ocorra. A primeira, diz respeito à abertura de espírito e à disposição do docente para relacionar o ensino com valores e atitudes que levem o aluno a exercer a posição de cidadão, participando das discussões e decisões na sua escola. A segunda atitude, refere-se 
à capacidade de questionar a prática, refletindo sobre a responsabilidade pessoal, acadêmica, social e política. A terceira, refere-se a sinceridade em fazer do ensino, a sua própria reflexão, isto é, estar aberto a diferentes opiniões, ser responsável e sincero em suas atitudes em sala de aula.

Para Schön (1983), a reflexão é um processo que ocorre antes e depois da ação e, em certa medida, durante a ação, pois os práticos têm conversas reflexivas com as situações que estão a praticar, enquadrando e resolvendo problemas em foco. Ao referenciar a prática reflexiva pedagógica, o PPC da LEdoC/UFPI enfatiza que é importante "o olhar crítico e reflexivo sobre a própria prática para possíveis ressignificações e reestruturações das propostas, contribuindo para a existência de um ambiente cooperativo, em que se possa aperfeiçoar as práticas educacionais" (UFPI, 2013, p. 78).

Zeichner (1993) rejeita as abordagens de cima para baixo das reformas educativas, nas quais os professores aplicam passivamente planos desenvolvidos por outros atores sociais, institucionais e ou políticos. Na perspectiva desse autor, os professores são práticos reflexivos que desempenham importantes papéis na definição das orientações das reformas educativas e na produção de conhecimentos sobre o ensino, graças a um trabalho de reflexão na e sobre a sua própria experiência.

Esse autor inova, em relação aos anteriores, na medida em que propõe a reflexividade crítica, enfatizando que o processo de ensino e aprendizagem se estende a todos os espaços de atuação do professor e que a emancipação deve ser inerente aos processos de formação, uma vez que, além da necessária relação entre teoria e prática, aprimoradas pela reflexão, é necessário considerar as condições sociais que envolvem professor e aluno, bem como, promover uma reflexão da prática que, no lugar de ser individual, deve ser contextualizada (ZEICHNER, 1993).

Em se tratando dos interlocutores do nosso estudo, professores de escolas do campo que são docentes e formandos ao mesmo tempo, inseridos em um processo de estudos teóricos e vivências profissionais, as oportunidades de reflexão sobre a prática e o contexto social campesino são as mais diversas. Nesse cenário, marcado pela diversidade de práticas e modelos de professores (academicistas, técnicos, práticos, reflexivos, críticos, militantes), os licenciandos têm a oportunidade de conhecer e refletir sobre os diferentes perfis profissionais, sobre o seu perfil, Cadernos Cajuína, V. 4, N. 1, 2019, p. 22 - 40.

ISSN: 2448-0916 
inclusive, adotando atitudes de empatia ou aversão, que podem interferir em aspectos das prática educativas que desenvolvem.

Ao adotarmos o princípio da reflexão crítica como relevante aspecto para a mudança da prática educativa de professores, consideramos as proposições de Freire (2014, p. 52) ao referir que a "práxis é reflexão e ação dos homens sobre o mundo para transformá-lo. Sem ela, é impossível a superação da condição opressor-oprimido". Dessa forma, entendemos que a mudança implica um processo de reflexão intensa sobre a sociedade e o fazer humano em diferentes dimensões, considerando ainda, suas implicações pessoais e sociais.

O princípio da reflexão crítica é de fundamental importância para a formação dos professores, seja por proporcionar mudanças de âmbito pessoal que refletem no ambiente de trabalho e atuação comunitária, seja por tornar o professor um profissional mais consciente e com capacidade de intervir diante das demandas e escolares e sociais.

\subsection{Racionalidade pedagógica de reconstrução social}

[...] um processo de formação participativa de educadores da reforma agrária para que estes possam desenvolver estratégias pedagógicas que visem à formação de sujeitos humanos autônomos e criativos capazes de produzir soluções para questões inerentes à sua realidade.

(UFPI, 2013, p. 27)

A perspectiva de reconstrução social congrega posições teóricas que concebem o ensino como uma atividade crítica, uma prática social de caráter ético, que se contrapõe à visão tradicional, técnica ou prática, compreendendo os professores como sujeitos humanos autônomos e criativos capazes de produzir soluções para questões inerentes à sua realidade, conforme epígrafe acima.

Nesse enfoque, o professor é visto como um profissional crítico, que reflete sobre a prática, mas também, sobre o contexto social em que a escola está inserida (PÉREZ GÓMEZ, 2000). Pelo histórico, proposições curriculares, bases teóricas e epistemológicas que orientam essa perspectiva, encontramos nela, fundamentos epistemológicos mais representativos do curso de Licenciatura em Educação do Campo, conforme revela fragmentos do PPC da LEdoC/UFPI: 
O profissional comprometido com a educação deve sempre preocupar-se em formar seu aluno a partir de uma visão crítica da sociedade, dando-lhe a oportunidade de expressar suas ideias, tornando-o um cidadão ativo e participante na vida social, cultural e política do seu povo. Agindo assim, o professor colocará em prática sua função política, exercendo sua mais importante atividade profissional - a mediação entre 0 aluno e a sociedade, seus conteúdos e especificidades. (UFPI, 2013, p. 78)

Conforme proposições destacadas, a perspectiva de reconstrução social possui estreita relação com a teoria crítica, aplicada ao currículo e ao ensino, sendo objetivo da formação, desenvolver a capacidade crítica dos formandos para análise do contexto social que rodeiam os processos de ensino e aprendizagem (GARCIA, 1999). Nesse sentido, é necessário que o currículo da formação ultrapasse os pressupostos da racionalidade técnica a da epistemologia da prática, contribuído para uma prática educativa, cuja ação exceda os muros das escolas, enxergando, criticando e encabeçando proposições, com vistas a superação das contradições sociais.

Contreras (2012) ao tratar sobre a perspectiva de reconstrução social, enfatiza que a prática profissional do professor crítico e reflexivo não contempla pretensões apenas educativas, mas se desdobra para a compreensão e transformação das desigualdades sociais, das injustiças que vitimam educandos e educadores. Reforça que é essa fraqueza ou insuficiência de argumentação do profissional reflexivo, que conduz a busca de uma concepção que, sem renunciar à pretensão reflexiva (uma prática consciente e deliberativa, guiada pela busca da coerência pessoal entre as atuações e convicções), dê conta dessas preocupações em relação a qual deveria ser a orientação para a reflexão do professor.

Giroux (1997) ao tratar sobre o intelectual crítico, propõe que os professores sejam formados para conhecer a natureza da dominação ideológica, possibilitandoos reconhecer as condições históricas em que vivem os sujeitos escolares, em qual meio eles estão inseridos, bem como, as forças contemporâneas que mantêm as condições de desigualdade social das quais alunos e professores são vítimas. Afirma ainda, a importância de os professores assumirem-se como intelectuais que trabalham no interesse de uma visão de emancipação. Para concretizá-la, segundo o autor, é necessário que sejam protagonistas na definição de políticas de formação e que tenham como elemento central, um projeto político mais amplo, coordenado 
por educadores intelectuais críticos, dispostos a desempenhar um papel central na luta por democracia e justiça social.

Nesse sentido, Molina; Hage (2015) afirmam que a Licenciatura em Educação do Campo deve oportunizar aos educadores, conhecimentos e experiências por meio dos quais eles superem a visão restrita dos limites e potenciais de sua ação, planejando e implementando, a partir de um contexto mais amplo, que envolva os processos sociais, econômicos, políticos e culturais envolvidos na relação escolacomunidade e nação.

$\mathrm{Na}$ perspectiva de construção social, prevalece o princípio da criticidade. Entendemos que, ao contemplá-lo, a formação contribui para uma prática intelectual crítica, capaz de interpretar os problemas e experiências da vida diária, desenvolvendo uma compreensão do que ocorre no ensino e fora dele, tornando os professores mais sensíveis ao que ocorre na sociedade e, notadamente, na vida dos sujeitos.

Apesar disso, concordamos com Formosinho (2009, p. 31) quando nos alerta que a frequência de um determinado modelo de formação "não é decisivo para a construção pessoal de uma definição de professor, pois, tal construção é mediada também pelos valores e personalidade de cada um, pela socialização ocupacional, pelas experiências de vida". Contudo, a frequência de uma perspectiva de formação e prática amplia as possibilidades de fomentar uma definição pessoal mais profissional de professor.

De forma semelhante, a Resolução no 2/2015, que define Diretrizes Curriculares Nacionais para a formação inicial em nível superior afirma que, "no exercício da docência, a ação do profissional do magistério da educação básica é permeada por dimensões técnicas, políticas, éticas e estéticas por meio de sólida formação, envolvendo o domínio e manejo de conteúdos e metodologias [...]" (BRASIL, 2015, p. 1).

Outrossim, questionamos: é interesse do Estado o desenvolvimento de políticas educacionais fundamentadas na perspectiva de reconstrução social, objetivando a mudança estrutural da sociedade e o rompimento com o modelo de desenvolvimento econômico? Como intelectuais críticos, ávidos por processos formativos contra-hegemônicos, atuam em estruturas administrativas burocráticas, coloniais e neoliberais? É possível formar professores com propósitos amplos e complexos, sem deixar de lado as dimensões básicas da docência? 


\section{CONSIDERAÇÕES FINAIS}

A análise das diferentes perspectivas que fundamentam a formação e prática educativa de professores, nos possibilitou perceber a complexidade do ser professor e a necessidade de que esse profissional adquira/desenvolva um leque de conhecimentos e saberes necessários ao exercício de sua profissão, assegurando a efetividade e qualidade social da ação educativa.

A formação de professores possui dimensão política e social, podendo atuar, tanto na formação de profissionais, cuja prática educativa promove atitudes e comportamentos que favoreçam a construção da realidade desejada para o presente e para o futuro, quanto para a manutenção e reprodução das atuais estruturas sociais, políticas e econômicas. Os professores podem ser conscientes ou não, da contribuição de sua prática educativa, no que se refere ao perfil de ser humano formado e sua relação com modelo almejado de sociedade, mas, quanto mais consciente e intencionado estiver, mais resultados alcançará por meio da mesma.

A verdade é que, o professor precisa desenvolver a sua prática educativa apoiado pelos conhecimentos técnicos, práticos e acadêmicos necessários ao exercício da profissão. Além disso, é imprescindível que tenha compromisso social e político para atuar na construção de uma sociedade justa, democrática, na qual o saber e o poder tenham equivalência.

Esse é, ao nosso ver, o desafio que está posto, não apenas para a Licenciatura em Educação do Campo, mas também, para todas as políticas de formação de professores - desenvolver professos formativos que proporcionem o domínio dos conhecimentos da área que ensina e da metodologia para ensinar, assegurando que a formação seja fundamentada em princípios, como reflexão, criticidade, de modo que o educador reflita e se conscientize que a sua responsabilidade é com o educando e a comunidade na qual está inserido.

\section{REFERÊNCIAS}

BRASIL. Conselho Nacional de Educação. Conselho Pleno. Resolução no 2/2015. Define as Diretrizes Curriculares Nacionais para a formação inicial em nível superior 
(Cursos de licenciatura, cursos de formação pedagógica para graduados e cursos de segunda licenciatura) e para a formação continuada. Brasília, DF: CNE, 2015.

CARSPECKEN, P. F. Pesquisa qualitativa crítica: conceitos básicos. Educ. Real., Porto Alegre, v. 36, n. 2, p. 395-424, maio/ago. 2011. Disponível em: < http://www.ufrgs.br/edu realidade >. Acesso em: 16 set. 2018.

CARVALHO, A. D. F. A racionalidade pedagógica da ação dos formadores de professores: um estudo sobre a epistemologia da prática docente nos cursos de licenciatura da Universidade Federal do Piauí. 2007. 239 f. Tese (Doutorado em Educação) - Universidade Federal do Ceará, Fortaleza, 2007.

CONTRERAS, J. Autonomia de professores. 2. ed. São Paulo: Cortez, 2012.

DEWEY, J. Como pensamos como se relaciona o pensamento reflexivo com o processo educativo: uma reexposição. Tradução: Haydée Camargo Campos. 4. ed. São Paulo: Nacional, 1979a. Atualidades Pedagógicas, v. 2, 292 p.

DEWEY, J. Democracia e educação. 4. ed. São Paulo: Companhia Editora Nacional, 1979.

FERNANDES, B. M. Educação do campo e território camponês no Brasil: In: SANTOS, C. A. (Org.). Campo, políticas públicas, educação. Brasília: INCRA; MDA, 2008. p. 39-66.

FORMOSINHO, J. (Coord.). Formação de professores: aprendizagem profissional e acção docente. Porto: Porto Editora, 2009.

GAMSCI, A. Os intelectuais e a organização da cultura. Rio de Janeiro: Civilização Brasileira, 1991.

GARCÍA, C. M. Formação de professores: para uma mudança educativa. Porto: Porto Editora, 1999.

GIROUX, H. A. Os professores como intelectuais: rumo a uma pedagogia crítica da aprendizagem. Tradução: Daniel Bueno. Porto Alegre: Artes Médicas, 1997.

KINCHELOE, J. L.; McLAREN, P. Repensando a teoria crítica e a pesquisa qualitativa. O planejamento da pesquisa qualitativa: teorias e abordagens. Tradução de Sandra Regina Netz. Porto Alegre: Artmed, 2006. p. 281-314.

MOLINA, M. C. Expansão das licenciaturas em Educação do Campo: desafios e potencialidades. Educar em Revista, Curitiba, Brasil, n. 55, p. 145-166, jan./mar., 2015. Editora UFPR.

MOLINA, M. C.; HAGE, S. M. Política e formação de educadores do campo no contexto da expansão da educação superior. Revista Educação em Questão, Natal, v. 51, n. 37, p. 121-146, jan./abr., 2015. 
PÉREZ GÓMEZ, A. I. Ensino para a compreensão. In: SACRISTAN, J. G.; PÉREZ GÓMEZ, A. I. Compreender e transformar o ensino. Porto Alegre: Artmed, 2000.

RICHARDSON, R. J. Pesquisa social: métodos e técnicas. São Paulo: Atlas, 2012.

SCHÖN, D. A. Educando o profissional reflexivo: um novo design para o ensino e a aprendizagem. Tradução Rober Cataldo Costa. Porto Alegre: Artmed, 1983.

SILVA, S. O Movimento de Educação do/no Campo: pressupostos fundamentais.

Educação em Revista, Marília, v 12, n 2, p. 7-22, Jul.-Dez., 2011. Disponível em: < http://www2.marilia.unesp.br/revistas/index.php/educacaoemrevista/article/view/2484 >. Acesso em: 22 ago. 2017.

TARDIF, M. Saberes docentes e formação profissional. Petrópolis: Vozes, 2011.

UNIVERSIDADE FEDERAL DO PIAUÍ. Proposta Pedagógica do Curso de Licenciatura em Educação do Campo/Ciências da Natureza. Teresina, 2013, 86 p.

ZEICHNER, K. M. A formação reflexiva de professores: ideias e práticas. Lisboa: Educa, 1993. 